\title{
Operating Performance Evaluation of Select MFIs- an empirical Analysis
}

\author{
Dr. S. Narasimha Chary ${ }^{1}$, Mr. Sreenivas Savvasi ${ }^{2}$ \\ ${ }^{1}$ Assistant Professor of Commerce \& Business Management, Kakatiya University, Warangal. \\ ${ }^{2}$ Ph.D. Research Scholar in the Department of Commerce \& Business Management, Kakatiya \\ University, Warangal
}

\section{Introduction:}

"Microfinance creates access to productive capital, which together with two other forms of capitalhuman capital, addressed through education and vocational training, and social capital, built through creating representative, local organization building, promoting democratic systems, and strengthening human rights; enables people to move out of poverty. Microfinance enables poor self-employed people to create productive capital, to protect the capital they have, to deal with risk, and to avoid the destruction of capital. It attempts to build assets and create wealth among people who lack them. For the very poor, microfinance becomes a liquidity tool that helps smooth their consumption patterns and to reduce their level of vulnerability.

The Institutions whose major business is the provision of financial services. Microfinance institutions are "those which provide thrift, credit and other financial services and products of very small amounts mainly to the poor in rural, semi-urban or urban areas for enabling them to raise their income level and improve living standards". A variety of microfinance institutions catering to the needs of poor exist in India. There are around 900 microfinance institutions with varied legal forms. MFIs are engaged in extending micro-credit loans - and often other financial services - to poor borrowers for income generating and self-employment activities.

\author{
Objectives: \\ This paper is outlined to analyse the following: \\ * To analyze the Cost per Borrower of select MFIs. \\ * To evaluate the Operating Expenses to Loan Portfolio of select MFIs. \\ * To examine Operating Expenses to Assets of select MFIs.
}

\section{Methodology:}

The data collected for the study includes secondary data. The various sources used to collect secondary data include research papers, journals, Status of Microfinance in India reports published by NABARD and various other websites. The secondary data collected is analyzed using various statistical tools and techniques such as mean, and one way ANOVA. The technique is used to identify if there exist a significant difference in the mean of different of select MFIs.

It is proposed to analyze the performance of select microfinance institutions. The data of eleven years (from 2001 to 2011) required for the analysis part have been collected through online database www.mixmarket.org. The analysis part is carried out with the help of the following variables:

\author{
Operating efficiency: \\ 1. Cost per Borrower \\ 2. Operating Expenses to Loan Portfolio \\ 3. Operating Expenses to Assets
}

\section{Cost per Borrower:}

Cost per borrower incurred by an MFI in the process of loan sanction in favour of borrower is considered as the operating cost commitment of concerned MFI. Lower the cost per borrower shall be the indication for high operational efficiency of the MFI. The data relevant to cost incurred by various microfinance institutions per borrower in extending loans are presented in table-1. 
Table - 1

Cost per Borrower of select Microfinance Institutions during the period from 2001 to 2011

(Amount in Rupees)

\begin{tabular}{|c|c|c|c|c|c|c|c|c|c|c|c|}
\hline Years & SKS & Spandana & SML & AML & SKDRDP & BSFL & Bandhan & $\mathrm{CMC}$ & GVMFL & GFSPL & Mean \\
\hline 2001 & 52 & 5 & 16 & & & & & 18 & 17 & 47 & 25.83 \\
\hline 2002 & 21 & 6 & 15 & & & & & 14 & 12 & 38 & 17.67 \\
\hline 2003 & 19 & 5 & 16 & & & & 8 & 12 & 13 & 27 & 14.29 \\
\hline 2004 & 16 & 5 & 17 & & & & 10 & 27 & 13 & 23 & 15.86 \\
\hline 2005 & 12 & 6 & 18 & 14 & 4 & 15 & 6 & 22 & 16 & 21 & 13.40 \\
\hline 2006 & 16 & 6 & 11 & 10 & 4 & 9 & 6 & 17 & 16 & 18 & 11.30 \\
\hline 2007 & 19 & 7 & 14 & 14 & 12 & 6 & 9 & 15 & & 27 & 13.67 \\
\hline 2008 & 19 & 9 & 15 & 15 & 5 & 5 & 8 & 15 & 18 & 21 & 13.00 \\
\hline 2009 & 16 & 10 & 13 & 13 & 5 & 5 & 7 & 15 & 17 & 18 & 11.90 \\
\hline 2010 & 18 & 12 & 13 & 15 & 6 & 7 & 10 & 16 & 23 & 23 & 14.30 \\
\hline 2011 & 21 & & & & & & & & & & 21.00 \\
\hline Mean & 20.82 & 7.10 & 14.80 & 13.50 & 6.00 & 7.83 & 8.00 & 17.10 & 16.11 & 26.30 & 13.76 \\
\hline
\end{tabular}

Source: Compiled from the database developed by Mierofinance Institutions Exchange (Mix market) for the period from 2001 to 11.

Figure - 1

Cost per Borrower pertaining to sample MFIs during the period from 2001-2011

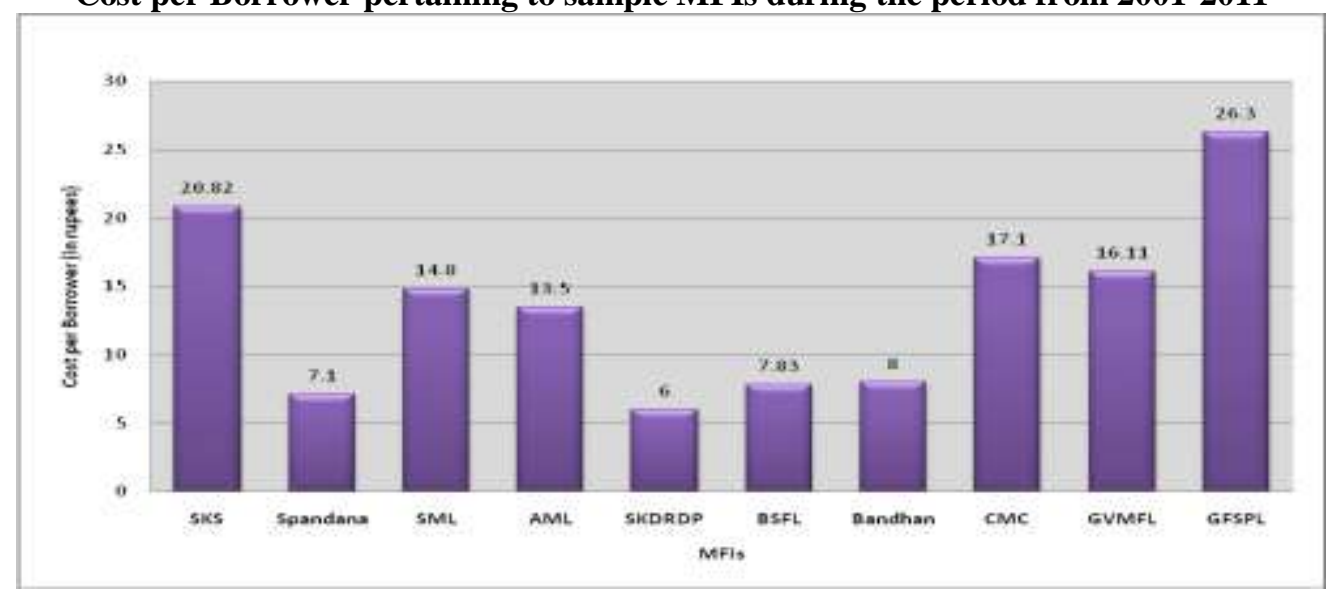

Source: Performed by using data of Mean cost per borrower compiled from table-1

The analysis of the data in table-1 and figure-1 disclose that the yearly industry cost per borrower recorded with a highest of Rs.25.83 in 2001 and lowest of Rs.11.30 in 2006 with an aggregate industry average of Rs.13.76 during the study period from 2001 to 2011.

The yearly cost per borrower compared with yearly industry average depicts that Spandana, Bandhan, and SKDRDP MFIs were performing well as their cost per borrower had been below the yearly industry average during all the years of the study period. In case of BSFL, the cost per borrower was also below the yearly industry average in all the years except in 2005. However, the operational efficiency of SML, SKS, AML, $\mathrm{CMC}$, GVMFL, and GFSPL was found below the stranded as the cost per borrower recorded above the yearly industry average during all most all the years of the study.

The aggregate analysis disclose that the Mean cost per borrower of Spandana with Rs.7.10, AML Rs.13.50, SKDRDP Rs.6.0, BSFL Rs.7.83, and Bandhan Rs.8.0 was found satisfactory as it was below the aggregate industry average of Rs.13.76, Where as, the yearly average cost per borrower of SKS with Rs.20.82, SML Rs.14.80, CMC Rs.17.10, GVMFL Rs.16.11, and GFSPL Rs.26.30 found above the yearly aggregate industry average.

The Mean cost per borrower of SKS, Spandana, SML, AML, SKDRDP, BSFL, Bandhan, CMC, GVMFL, and GFSPL have been compared by performing one way ANOVA with the following null hypothesis which was tested at $5 \%$ level of significance and results are shown table-2. 
Table-2

ANOVA Result of cost per borrower

\begin{tabular}{|l|c|c|c|c|}
\hline SUMMARY & & & & \\
\hline Groups & Count & Sum & Average & Variance \\
\hline SKS & 11 & 229 & 20.81818 & 113.7636 \\
\hline Spandana & 10 & 71 & 7.1 & 5.877778 \\
\hline SML & 10 & 148 & 14.8 & 4.4 \\
\hline AML & 6 & 81 & 13.5 & 3.5 \\
\hline SKDRDP & 6 & 36 & 6.0 & 9.2 \\
\hline BSFL & 6 & 47 & 7.833333 & 14.56667 \\
\hline Bandhan & 8 & 64 & 8.0 & 2.571429 \\
\hline CMC & 10 & 171 & 17.1 & 19.21111 \\
\hline GVMFL & 9 & 145 & 16.11111 & 11.11111 \\
\hline GFSPL & 10 & 263 & 26.3 & 86.9 \\
\hline
\end{tabular}

\begin{tabular}{|l|c|c|c|c|c|c|}
\hline ANOVA & & & & & & \\
\hline Source of Variation & $S S$ & $D f$ & $M S$ & $F$ & P-value & F crit \\
\hline Between Groups & 3514.39723 & 9 & 390.489 & 12.2211 & $1.02 \mathrm{E}-11$ & 2.005543 \\
\hline Within Groups & 2428.35859 & 76 & 31.9521 & & & \\
\hline Total & $\mathbf{5 9 4 2 . 7 5 5 8 1}$ & $\mathbf{8 5}$ & & & & \\
\hline
\end{tabular}

Source: ANOVA Performed by using MS-Excel software based an the data compiled in table-1

Ho: The Mean cost per borrower of SKS, Spandana, SML, AML, SKDRDP, BSFL, Bandhan, CMC, GVMFL, and GFSPL do not differ significantly.

Inference: The null hypothesis stands rejected since the calculated value of " $F "=12.221$ is greater than the table value of $\mathrm{F}$ (crit) $=2.0055$. As such, it can be inferred that there is significant difference of Mean cost per borrower among the entire sample MFIs.

\section{Operating Expenses to Loan Portfolio:}

The cost incurred by an MFI at the time of sanctioning and disbursing loan among various SHGs and other individual borrowers as percent to gross loan portfolio has been considered for analysis. The data pertaining to operating expenses to loan portfolio is presented in table -3 .

Table -3

Operating Expenses to Loan Portfolio of select Microfinance Institutions during the period from 2001 to 2011

(In percent)

\begin{tabular}{|c|c|c|c|c|c|c|c|c|c|c|c|}
\hline Years & SKS & Spandana & SML & AML & SKDRDP & BSFL & Bandhan & CMC & GVMFL & GFSPL & Mean \\
\hline $\mathbf{2 0 0 1}$ & 57.53 & 6.55 & 23.59 & & & & & 26.59 & 37.40 & 77.69 & $\mathbf{3 8 . 2 3}$ \\
\hline $\mathbf{2 0 0 2}$ & 25.52 & 7.13 & 19.96 & & & & & 18.01 & 23.23 & 62.80 & $\mathbf{2 6 . 1 1}$ \\
\hline $\mathbf{2 0 0 3}$ & 73.94 & 5.14 & 18.54 & & & & & 13.33 & 21.88 & 41.83 & $\mathbf{2 9 . 1 1}$ \\
\hline $\mathbf{2 0 0 4}$ & 15.07 & 4.11 & 15.94 & & & & 21.48 & 29.00 & 19.75 & 27.89 & $\mathbf{1 9 . 0 3}$ \\
\hline $\mathbf{2 0 0 5}$ & 10.47 & 5.82 & 15.17 & 13.69 & 3.91 & 7.01 & 11.81 & 23.68 & 21.32 & 18.30 & $\mathbf{1 3 . 1 2}$ \\
\hline $\mathbf{2 0 0 6}$ & 13.22 & 6.08 & 10.59 & 9.98 & 3.30 & 6.69 & 8.76 & 17.88 & 16.79 & 13.93 & $\mathbf{1 0 . 7 2}$ \\
\hline $\mathbf{2 0 0 7}$ & 12.32 & 5.79 & 10.67 & 10.72 & 8.86 & 5.79 & 10.44 & 13.34 & & 17.57 & $\mathbf{1 0 . 6 1}$ \\
\hline $\mathbf{2 0 0 8}$ & 13.31 & 6.17 & 9.48 & 9.75 & 4.16 & 5.98 & 8.78 & 13.00 & 17.08 & 12.32 & $\mathbf{1 0 . 0 0}$ \\
\hline $\mathbf{2 0 0 9}$ & 10.14 & 5.36 & 8.20 & 6.34 & 4.78 & 5.48 & 5.43 & 11.43 & 11.79 & 9.54 & $\mathbf{7 . 8 5}$ \\
\hline $\mathbf{2 0 1 0}$ & 10.62 & 6.08 & 6.82 & 6.76 & 4.12 & $\mathbf{5 . 4 1}$ & 6.12 & 12.09 & 15.47 & 13.33 & $\mathbf{8 . 6 8}$ \\
\hline $\mathbf{2 0 1 1}$ & 14.42 & & & & & & & & $\mathbf{1 4}$ \\
\hline Mean & $\mathbf{2 3 . 3 2}$ & $\mathbf{5 . 8 2}$ & $\mathbf{1 3 . 9 0}$ & $\mathbf{9 . 5 4}$ & $\mathbf{4 . 8 6}$ & $\mathbf{6 . 0 6}$ & $\mathbf{1 0 . 4 0}$ & $\mathbf{1 7 . 8 4}$ & $\mathbf{2 0 . 5 2}$ & $\mathbf{2 9 . 5 2}$ & $\mathbf{1 4 . 1 8}$ \\
\hline
\end{tabular}

Source: Compiled from the Mierofinance Institutions Exchange (Mix market) for the period from 2001 to 2011. 
Figure - 2

Operating Expenses to Loan Portfolio Sample MFIs during the period from 2001-2011

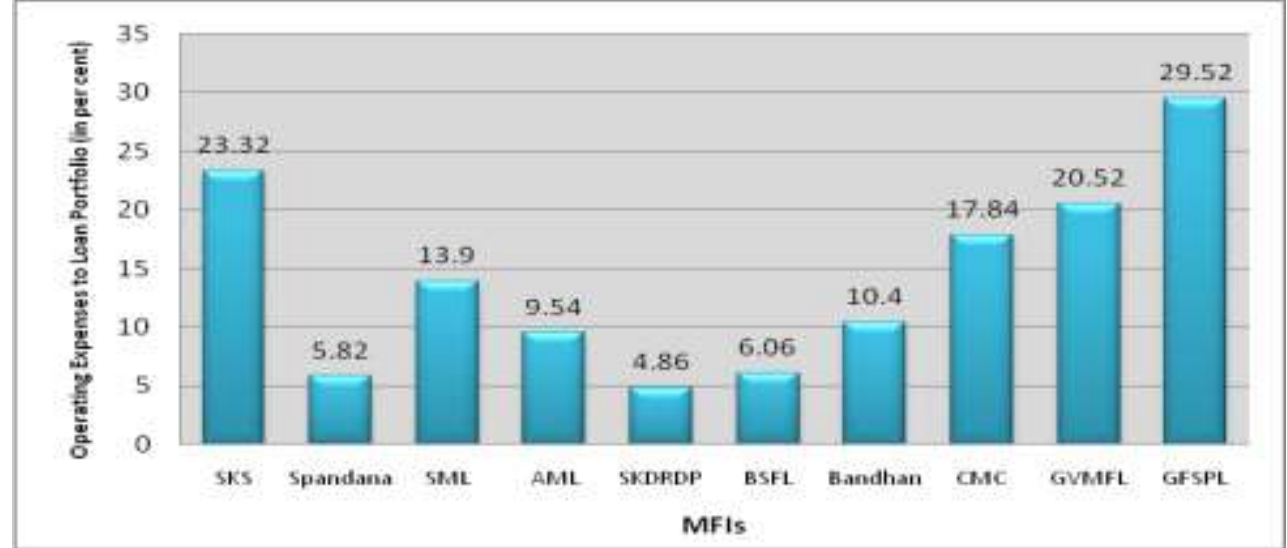

Source: Performed by using data of Mean Operating expenses to Loan Portfolio compiled in table-3

The analysis of data in table- 3 and figure- 2 disclose that the ratio of operating expenses as to loan portfolio of Indian Microfinance industry varied between the highest of 38.23 times in 2001 and lowest of 7.85 times in 2009 with the aggregate industry average 14.18 times during the study period 2001 to 2011 . The lower ratio indicates high operational efficiency and there by yielding high profitability. Spandana, SKDRDP, BSFL, Bandhan MFIs have operated well in maintaining their operating expenses to loan portfolio ratio was below the yearly industry average in all the years of the study. However, the operating expenses ratio of SKS, CMC, GVMFL, and GFSPL MFIs recorded above the yearly industry average during most of the years during the period of the study in general and particularly during the period from 2006 to 2011 as this ratio was found adverse as compared to that of the yearly industry average.

The aggregate analysis indicates that the Spandana, SML, AML, SKDRDP, BSFL, and Bandhan were the most efficient companies which able to maintain the yearly average operating expenses ratios accounted for 5.82 times, 13.9 times, 9.54 times, 4.86 times, 6.06 times, and 10.4 times respectively found at lower than that of aggregate industry average of 14.18 times during the study period. Further, it has been noted that SKS, CMC, GVMFL, and GFSPL were maintained their average operating expenses ratio of 23.23 times, 17.84 times, 20.52 times, and 29.52 times respectively were higher than that of aggregate industry average.

The data pertaining to the Mean ratio of operating expenses as to loan portfolio are compared and analyzed by performing one way ANOVA with the following hypothesis and the results are disclosed in table-4.

Table -4

ANOVA Result of operating expenses to loan portfolio

\begin{tabular}{|l|c|c|c|c|}
\hline SUMMARY & & & & \\
\hline Groups & Count & Sum & Average & Variance \\
\hline SKS & 11 & 256.56 & 23.32364 & 470.8156 \\
\hline Spandana & 10 & 58.23 & 5.823 & 0.678401 \\
\hline SML & 10 & 138.96 & 13.896 & 31.27394 \\
\hline AML & 6 & 57.24 & 9.54 & 7.3642 \\
\hline SKDRDP & 6 & 29.13 & 4.855 & 4.07599 \\
\hline BSFL & 6 & 36.36 & 6.06 & 0.42752 \\
\hline Bandan & 7 & 72.82 & 10.40286 & 28.84822 \\
\hline CMC & 10 & 178.35 & 17.835 & 41.49003 \\
\hline GVMFL & 9 & 184.71 & 20.52333 & 52.85285 \\
\hline GFSPL & 10 & 295.2 & 29.52 & 561.2218 \\
\hline
\end{tabular}

\begin{tabular}{|l|c|c|c|c|c|c|}
\hline ANOVA & & & & & & \\
\hline \multicolumn{1}{|c|}{ Source of Variation } & $S S$ & $d f$ & $M S$ & $F$ & $P$-value & F crit \\
\hline Between Groups & 5491.116 & 9 & 610.124 & 4.131622 & 0.000239 & 2.00726 \\
\hline Within Groups & 11075.38 & 75 & 147.6718 & & & \\
\hline Total & $\mathbf{1 6 5 6 6 . 5}$ & $\mathbf{8 4}$ & & & & \\
\hline
\end{tabular}

Source: ANOVA Performed by using MS-Excel software based and the data compiled in table-3. 
Ho: There is no significance difference among SKS, Spandana, SML, AML, SKDRDP, BSFL, Bandhan, CMC, GVMFL, and GFSPL MFIs as far as the Mean ratio of operating expenses to loan portfolio is concerned.

Inference: Since the calculated value of "F"= 4.131622 is grater than the table value of Fcrit $=2.00726$, the hypothesis stands rejected. As such, it can be inferred that the Mean ratio of operating expenses to loan portfolio among the sample MFIs differ significantly.

\section{Operating Expenses to Assets:}

An expense ratio is calculated by dividing the operating expenses by the total assets. It is also known as management expense ratio. The lower the ratio implies that the institution is more profitable and shows its ability to cover the costs effectively. The ratio of operating expenses to Assets of Indian Microfinance Industry is depicted in table-5

Table -5

Operating expenses to Assets of sample Microfinance Institutions during the period from 2001 to 2011 (In percent)

\begin{tabular}{|c|c|c|c|c|c|c|c|c|c|c|c|}
\hline Years & SKS & Spandana & SMI & AML & SKDRDP & BSFL & Bandhan & $\mathrm{CMC}$ & GVMFL & GFSPL & Mean \\
\hline 2001 & 31.56 & 5.93 & 19.07 & & & & & 17.53 & 19.79 & 50.30 & 24.03 \\
\hline 2002 & 18.21 & 6.63 & 16.71 & & & & & 12.09 & 15.11 & 40.94 & 18.28 \\
\hline 2003 & 12.37 & 4.62 & 15.37 & & & & & 10.29 & 15.63 & 26.59 & 14.15 \\
\hline 2004 & 11.75 & 3.59 & 13.85 & & & & 17.58 & 21.66 & 12.43 & 20.32 & 14.45 \\
\hline 2005 & 8.22 & 5.05 & 13.08 & 11.34 & 3.34 & 5.95 & 10.86 & 18.28 & 9.43 & 13.38 & 9.89 \\
\hline 2006 & 10.50 & 5.33 & 9.28 & 8.34 & 2.56 & 5.85 & 8.27 & 14.88 & 10.65 & 11.06 & 8.67 \\
\hline 2007 & 9.63 & 5.08 & 8.92 & 8.80 & 6.62 & 5.01 & 8.75 & 11.86 & & 13.81 & 8.72 \\
\hline 2008 & 10.62 & 5.97 & 8.53 & 7.90 & 3.29 & 4.82 & 6.68 & 13.56 & 13.95 & 12.23 & 8.76 \\
\hline 2009 & 9.80 & 6.14 & 6.14 & 5.15 & 3.94 & 4.06 & 4.18 & 11.89 & 11.06 & 10.64 & 7.30 \\
\hline 2010 & 10.84 & 7,00 & 5.54 & 5.84 & 3.04 & 4.08 & 5.11 & 10.86 & 15.60 & 11.42 & 7.93 \\
\hline 2011 & 18.61 & & & & & & & & & & 18.61 \\
\hline Mean & 13.83 & 5.53 & 11.65 & 7.90 & 3.80 & 4.96 & 8.78 & 14.29 & 13.74 & 21.07 & 10.55 \\
\hline
\end{tabular}

Figure -3

Operating Expenses to Assets of Sample MFIs during the period from 2001 to 2011

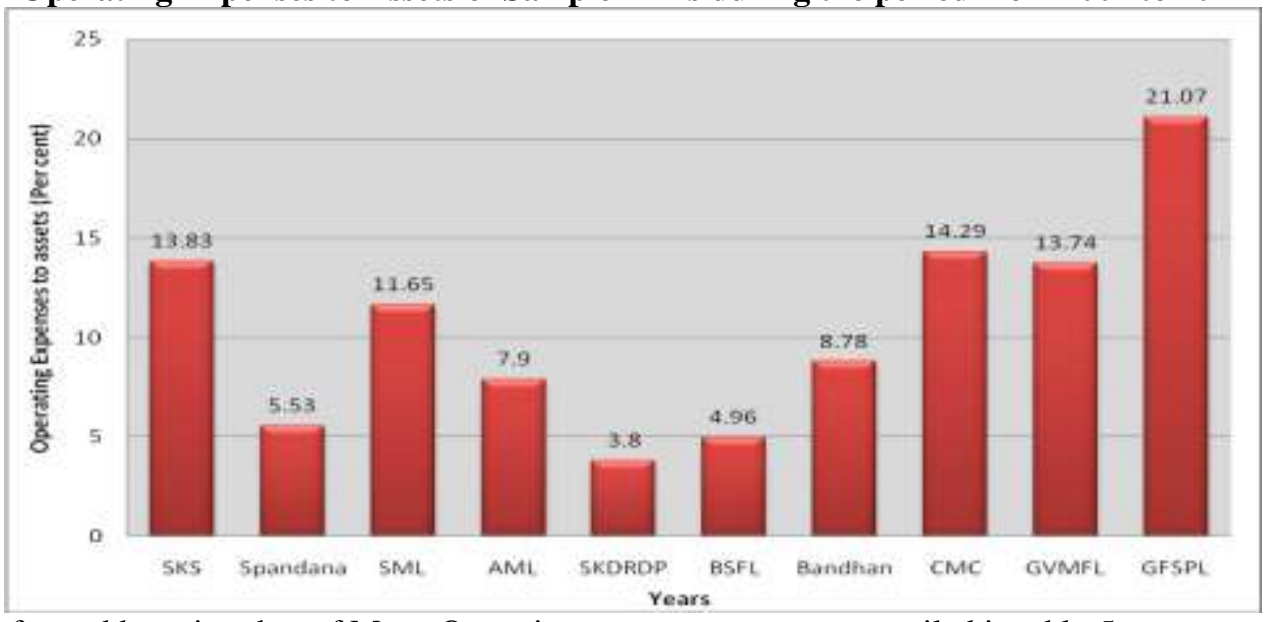

Source: Performed by using data of Mean Operating expenses to assets compiled in table-5

The analysis of data in table-5 and figure- 3 disclose that the ratio of operating expenses to total assets of Indian Microfinance Industry varied between the highest of 24.03 times in 2001 and the lowest of 7.30 times in 2009 with eleven years average of 10.55 times during the study period 2001 to 2011.

Year wise analysis indicate that the operating expenses to assets ratio of SPANDANA, SKDRDP, and BSFL microfinance institutions ranged between lowest of 3.59 times, 2.56 times, 4.06 times respectively and 
highest of 7.0 times, 6.62 times, and 5.95 times respectively which were below the yearly industry average during all the years of study. This reflects these that MFIs have been operating well in controlling such operating expenses which leads to achieve high profitability. AML could also able to maintain lower ratio in all the years except in the years 2005 and 2007. In case of GFSPL, it could in vain in maintaining its ratio lower than yearly industry average in all the years from 2001 to 2011. SKS maintained lower ratio during 2002 to 2005 and thereafter it has turned into above the yearly industry average during the years 2006 to 2010. SML was also in vain in maintaining lower ratio except in the years 2001, 2002, 2004, 2009, and 2010. Bandhan has been improving its efficiency from 2008 onwards where its ratio was below the yearly industry average during the period from 2008 to 2011. However, CMC and GVMFL could unable to maintain their operating expenses to assets ratio below the yearly industry average during the period from 2004 and 2006 respectively to 2011 .

The analysis also disclose that SKS, SML, CMC, GVMFL, and GFSPL Microfinance institutions could not maintain their operating expenses to assets ratio below the industry average in aggregate, whereas, Spandana, AML, SKDRDP, BSFL, and Bandhan microfinance institutions could operate well in maintaining their ratio below the industry average which have been accounted for 5.53 times, 7.90 times, 3.80 times, 4.96 times and 8.78 times respectively during the study period. However, SKS with operating expenses to assets ratio of 13.83 times, SML with 11.65 times, CMC with 14.29 times, GVMFL with 13.74 times, and GFSPL with 21.07 found above the aggregate industry average of 10.55 times over the period of study, as such it has been clearly reflected that these MFIs could unable to control the operating expenses, as such, negative impact on profitability would be expected accordingly.

The operating expenses to total Assets are higher for some of the microfinance institutions. The reason for this is the MFIs have incurred training expenses for their staff members, education of borrowers etc. Also, the delivery model of MFIs at the doorstep of borrowers is a reason for the MFIs to have incurred high operating costs.

The data pertaining to the Mean ratio of operating expenses as to Total assets are compared and analyzed by performing one way ANOVA with the following hypothesis and the results are disclosed in table- 6 .

Table - 6

ANOVA Result of operating expenses to Assets

\begin{tabular}{|l|c|c|c|c|}
\hline \multicolumn{5}{c|}{ SUMMARY } \\
\hline Groups & Count & Sum & Average & Variance \\
\hline SKS & 11 & 152.11 & 13.82818 & 45.85298 \\
\hline Spandana & 10 & 55.34 & 5.534 & 1.017893 \\
\hline SML & 10 & 116.49 & 11.649 & 21.31997 \\
\hline AML & 6 & 47.37 & 7.895 & 4.92863 \\
\hline SKDRDP & 6 & 22.79 & 3.798333 & 2.111777 \\
\hline BSFL & 6 & 29.77 & 4.961667 & 0.675737 \\
\hline Bandan & 7 & 61.43 & 8.775714 & 20.1777 \\
\hline CMC & 10 & 142.9 & 14.29 & 13.98727 \\
\hline GVMFL & 9 & 123.65 & 13.73889 & 10.32224 \\
\hline GFSPL & 10 & 210.69 & 21.069 & 196.9266 \\
\hline
\end{tabular}

\begin{tabular}{|l|c|c|c|c|c|c|}
\hline \multicolumn{1}{|c|}{ ANOurce of Variation } & $S S$ & $d f$ & $M S$ & $F$ & P-value & $F$ crit \\
\hline Between Groups & 2194.079 & 9 & 243.7865 & 6.529949053 & $8.11415 \mathrm{E}-07$ & 2.00726 \\
\hline Within Groups & 2800.02 & 75 & 37.3336 & & & \\
\hline Total & $\mathbf{4 9 9 4 . 0 9 9}$ & $\mathbf{8 4}$ & & & & \\
\hline
\end{tabular}

Source: ANOVA Performed by using MS-Excel software based an the data compiled in table-5

Ho: The Mean Operating Expenses to Assets ratio of SKS, Spandana, SML, AML, SKDRDP, BSFL, Bandhan, CMC, GVMFL, GFSPL microfinance institutions do not differ significantly.

Inference: There is significant difference in the operating expenses to total assets ratio of MFIs at 5\% level of significance, thereby rejecting null hypothesis since the calculated value of "F" $=6.529949053$ is greater than the table value of Fcrit $=2.00726$. As such it can be inferred that the Mean ratio of operating expenses to loan portfolio among the sample MFIs differ significantly. 


\section{Conclusion:}

The aggregate analysis disclose that the Mean cost per borrower of Spandana with Rs.7.10, AML Rs.13.50, SKDRDP Rs.6.0, BSFL Rs.7.83, and Bandhan Rs.8.0 was found satisfactory as it was below the aggregate industry average of Rs.13.76, Where as, the yearly average cost per borrower of SKS with Rs.20.82, SML Rs.14.80, CMC Rs.17.10, GVMFL Rs.16.11, and GFSPL Rs.26.30 found above the yearly aggregate industry average.

The aggregate analysis indicates that the Spandana, SML, AML, SKDRDP, BSFL, and Bandhan were the most efficient companies which able to maintain the yearly average operating expenses ratios accounted for 5.82 times, 13.9 times, 9.54 times, 4.86 times, 6.06 times, and 10.4 times respectively found at lower than that of aggregate industry average of 14.18 times during the study period. Further, it has been noted that SKS, CMC, GVMFL, and GFSPL were maintained their average operating expenses ratio of 23.23 times, 17.84 times, 20.52 times, and 29.52 times respectively were higher than that of aggregate industry average.

The analysis also disclose that SKS, SML, CMC, GVMFL, and GFSPL Microfinance institutions could not maintain their operating expenses to assets ratio below the industry average in aggregate, whereas, Spandana, AML, SKDRDP, BSFL, and Bandhan microfinance institutions could operate well in maintaining their ratio below the industry average which have been accounted for 5.53 times, 7.90 times, 3.80 times, 4.96 times and 8.78 times respectively during the study period. However, SKS with operating expenses to assets ratio of 13.83 times, SML with 11.65 times, CMC with 14.29 times, GVMFL with 13.74 times, and GFSPL with 21.07 found above the aggregate industry average of 10.55 times over the period of study, as such it has been clearly reflected that these MFIs could unable to control the operating expenses, as such, negative impact on profitability would be expected accordingly.

\section{References:}

[1] Aiain de Crombrugghe, Michael Tenike and Julie Sureda (2007), Performance Analysis for a Sample of Microfinance Institutions in India, Annals public and Corporative Economics 79:2 2008, pp. 269-299.

[2] Asian Development Bank (2000), (Asian Development Bank Final Report 2000).

[3] Jayashhela, Dinesha.P.T and V. Basil Hans (2008), Financial inclusion and microfinance in India: An Overview" http://india. Microsav.org/node/1270.

[4] Joseph P. Kaboski and Robert M. Townsend (2005), "Policies and Impact: An Analysis of Village-level Microfinance institutions", Journal of the European Economic Association March 2005 3(1): 1-50.

[5] Jyothi (2010), Indian Journal of Finance, Vol: 4, No: 3 March 2010

[6] K.K. Tripathy (2004), Self- Help Groups: A Catalyst of Rural Development, Kurukshetra, Vol. 52, No.8, and June, 2004.

[7] Kropp, Erhard, W. and B.S. Suran, (2002), "Linking Banks and (Financial) Self Help Groups in India -An Assessment", Paper presented at the Seminar on SHG bank Linkage Programme at New Delhi, November 25-26, 2002.

[8] Puhazhendi V. Badatya K.C (2002), "SHG Bank Linkage programme for Rural Poor-an Impact Assessment", www. NABARD.org.2002.

[9] Purna Chandra Parida and Anushree Sinha (2010), "Performance and Sustainability of Self-help Groups in India: A Gender Perceptive. 